\title{
Preparation, Characterization and
}

\section{Antimicrobial Studies of Mn(II) and Fe(II) Complexes with Schiff Base Ligand Derived from 2-aminophenol and 3-formyl-2-hydroxy-6-methoxyquinoline}

\author{
Abubakar Muhammad Jabbi 1* , Habu Nuhu Aliyu', \\ Sulaiman Isyaku ${ }^{3}$, Abdullahi Muhammad Kabir ${ }^{2}$ \\ ${ }^{1}$ Department of Chemistry, Federal Science and Technical College Dayi, Katsina, Nigeria \\ ${ }^{2}$ Department of Pure and Industrial Chemistry, Bayero University Kano, Kano, Nigeria \\ ${ }^{3}$ Department of Pure and Industrial Chemistry, Ahmadu Bello University, Zaria, Nigeria \\ Email: *abubakarmuhammadjabbi@gmail.com
}

How to cite this paper: Jabbi, A.M., Aliyu, H.N., Isyaku, S. and Kabir, A.M. (2020) Preparation, Characterization and Antimicrobial Studies of $\mathrm{Mn}$ (II) and Fe(II) Complexes with Schiff Base Ligand Derived from 2-aminophenol and 3-formyl-2-hydroxy-6-methoxyquinoline. Open Journal of Inorganic Chemistry, 10, 15-24.

https://doi.org/10.4236/ojic.2020.102003

Received: April 6, 2020

Accepted: April 27, 2020

Published: April 30, 2020

Copyright $\odot 2020$ by author(s) and Scientific Research Publishing Inc. This work is licensed under the Creative Commons Attribution International License (CC BY 4.0).

http://creativecommons.org/licenses/by/4.0/

\begin{abstract}
Schiff base derived from 2-aminophenol and 3-formyl-2-hydroxy-6-methoxyquinoline and its $\mathrm{Mn}$ (II) and Fe(II) complexes were synthesized and characterized by melting point and decomposition temperature, elemental analysis, molar conductivity, infrared (IR) spectral analysis, atomic absorption spectroscopy (AAS) analysis, solubility test, and magnetic susceptibility. The Fourier-transform infrared spectroscopy (FTIR) spectral data of the Schiff base determined showed a band at $1622 \mathrm{~cm}^{-1}$ and this was assigned to the ${ }_{V}(\mathrm{C}=\mathrm{N})$, which is a feature of azomethine group. The same band was observed to shift to lower frequencies 1577 and $1599 \mathrm{~cm}^{-1}$ in the complexes suggesting coordination of the Schiff base with the respective metal(II) ions. Molar conductance values 14.58 and $12.65 \Omega^{-1} \cdot \mathrm{cm}^{2} \cdot \mathrm{mol}^{-1}$ show that the metal complexes were non-electrolyte in nature. The magnetic susceptibility of the complexes was determined and the gram magnetic susceptibility of the complexes was found to be positive, revealing that they are paramagnetic. The elemental analysis of the complexes for $\mathrm{C}, \mathrm{N}$ and $\mathrm{H}$ determined suggested 1:1 metal to ligand ratio. The result of the antimicrobial studies showed that, the metal(II) complexes exhibited better antibacterial and antifungal activity than the Schiff base.
\end{abstract}

\section{Keywords}

Metal(II) Complexes, Schiff Base, Antibacterial and Antifungal Studies 


\section{Introduction}

Schiff base is a compound containing an imine or azomithine group, $(-\mathrm{N}=\mathrm{CH}-)$. It is a condensation product of aldehyde or ketone with primary amine and was first reported in 1864 by a German chemist Hugo Schiff [1]. Schiff base is a very important structure for synthetic organic chemistry. These compounds are usually characterized by an imine functional group $(-\mathrm{N}=\mathrm{CH}-)$, that helps us to clarify the mechanism, racemization and transamination interaction in biological system [2]. Azomithune nitrogen in the Schiff base, is of considerable chemical and biological importance, and not only provides binding sites for metal ions but also makes attachments with various substrate of bio-molecules like proteins and amino acids in biological systems and that of diseases-causing germs [3]. These compounds play an important role in medicinal fields because of their wide spectrum of biological activities. Many of them have antimicrobial and anticancer effect as biologically important compounds [4].

Apart from their biological effect, they are used in many fields such as pigments, dyes, fungicidal, corrosion inhibitors, analytical chemistry, polymer stabilizers, agrochemical, ion exchange, electrical conductivity catalysis, nonlinear optics and magnetism [5]. Schiff base is changeable molecule and can be bi- or tridentate ligands capable of producing very stable complexes with transition metals like nickel, iron, cobalt, copper, vanadium etc. Most of the metal chelates have higher antibacterial and antifungal activities than the individual ligands [6]. The biological implementations and chelating ability of metal complexes have attracted a significant concern. Transition metal complexes have been widely studied due to their various biological applications in pharmacological areas [7]. These complexes were reported to have antitumor, anti-inflammatory, antioxidan, antimalarial, and antimicrobial activities [8] [9]. Metal complexes with N, O as their donor atoms are very noticeable because of their important biological activities like anticancer, and herbicidal activity [10]. In this study the Schiff base of 3-[(2-hydroxy-phenylimino)-methyl]-6-methoxy-quinolin2-ol was synthesized from 2-aminophenol and 2-hydroxy-6-methoxy-3-quinlinecarboxaldehyde and its divalent metal complexes were prepared. The ligand and metal complexes were further characterized and their antimicrobial activity was also determined.

\section{Material and Methods}

\subsection{Chemicals, Reagents and Apparatus}

All the reagents and chemicals used in this research work were of analytical grade and used without further purification. All weighing were carried out using an electric balance model AB54. The IR spectral analysis was recorded using Cary 630 FTIR Agilent Technologies. Conductivity measurement was carried out in dimethylsulfoxide (DMSO) solvent using Jenway 4010 conductivity meter. Melting point and decomposition temperature measurements were obtained with a SMP10 STUART melting point apparatus. Elemental Analysis was con- 
ducted at Micro Analytical Centre OEA labs, United Kingdom, using CE Instrument (Thermo) EA1110 Elemental Analyser. The antimicrobial activity of ligand and metal complexes were tested in vitro against bacteria Staphylococcus aureus, Escherichia coli and Klebsiella pneumoniae by paper disc plate method and compared with known antibiotics, Gentamycin. For the fungicidal activity, compounds were screened in vitro against Aspergillus fumigatus, Aspergillus flavus and Aspergillus niger by the same method which compared with Ketaconazole. The antimicrobial activity studies were carried out at the Department of Microbiology, Bayero University, Kano.

\subsection{Synthesis of the Intermediate: 2-hydroxy-6-methoxy-3-quinolinecarboxaldehyde}

2-chloro-6-methoxy-3-quinolinecarboxaldehyde $(2.4 \mathrm{~g}, 0.01 \mathrm{~mol})$ was added to aqueous hydrochloric acid (35 ml, $4 \mathrm{~mol}$ ) and the subsequent solution was heated under reflux on water bath for about 1 hour. Also the subsequent mixture was cooled to room temperature. 2-hydroxy-6-methoxy-3-quinlinecarboxaldehyde was filtred, washed thoroughly with cold ethanol followed by diethilether into yellow cotton-like; the reaction is shown in (Scheme 1).

\subsection{Preparation of the Schiff Base Ligand}

The Schiff base ligand was synthesized by condensation of 3-formyl-2-hydroxy6-methoxyquinoline $(0.01 \mathrm{~mol})$ with 2 -aminophenol $(0.01 \mathrm{~mol})$ in ethanol and refluxing on water bath for six to seven $(6-7) \mathrm{hrs}$ in the presence of three to four drops of acetic acid. Subsequently, the reaction mixture was cooled to room temperature and then the ligand was seperated by filteration, washed thoroughly with cold ethanol followed by diethylether to get a pure sample. The chemical reaction is represented in (Scheme 2).

\subsection{Synthesis of the Metal(II) Schiff Base Complexes}

To the hot solution of (0.001 mol) 3-[(2-Hydroxy-phenylimino)-methyl]-6-me-<smiles>COc1ccc2nc(Cl)c(C=O)cc2c1</smiles>

Scheme 1. Synthesis of 2-hydroxy-6-methoxy-3-quinolinecarboxaldehyde.

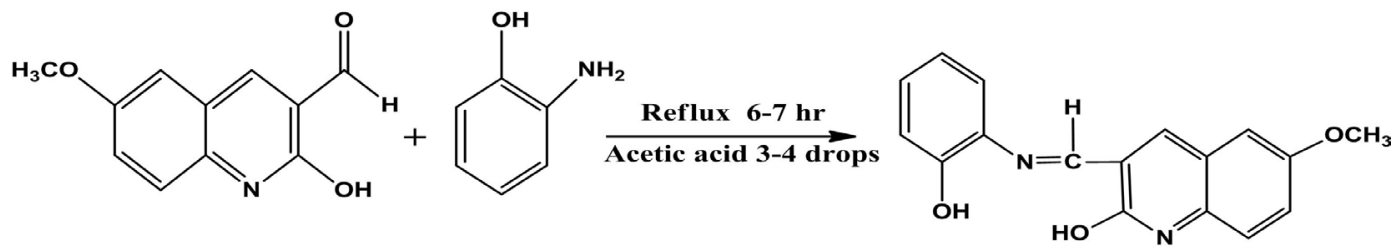

Scheme 2. Formation of the Schiff base. 
thoxy-quinolin-2-ol in $\left(35 \mathrm{~cm}^{3}\right)$ ethanol, a hot ethanolic solution of $(0.001 \mathrm{~mol})$ metal(II) chlorides in ethanol $\left(15 \mathrm{~cm}^{3}\right)$ was added. The subsequent solution was refluxed on a water bath for $4-5$ hours to get a clear solution. Also $0.5 \mathrm{~g}$ of excess sodium acetate $\mathrm{CH}_{3} \mathrm{CHNa}$, was added to the reaction mixture to shift the $\mathrm{pH}$ (7 to 8) of the solution and the refluxing was continued for 2 more hours. The subsequent reaction mixture was then segregated by pouring into distilled water $\left(100 \mathrm{~cm}^{3}\right)$ with continuous stirring. Then the yellow compound obtained was left to settle and separated out by filtration, washed with distilled water, then with hot ethanol and cold diethylether and dried in vacuum over phosphorus pentoxide.

\subsection{Physical Measurements}

The IR spectroscopy of the Schiff base and its metal(II) complexes were recorded employing FTIR Carry Agilent 630 spectrophotometer at $4000-650 \mathrm{~cm}^{-1}$ region in $\mathrm{KBr}$ pellets. $\mathrm{C}, \mathrm{H}$ and $\mathrm{N}$ were estimated employing elemental analyzer Perkin-Elmer model 240c. Jenway 4010 conductivity meter was used in conductivity measurement using DMSO as solvent. Melting point and decomposition temperature were obtained by using SMP10 STUART melting point apparatus. The magnetic susceptibility of the complex was measured on Gouy's balance at room temperature.

\subsection{Antibacterial Activity Test}

The method used by Jorgensen (Jorgensen, and Turnidge, 2003) was used in antibacterial test, in which the Schiff base and its metal(II) complexes were assayed by ager disc diffusion method using cultures of Escherichia coli, Salmonella typhi and Staphylococcus aureus. The samples were separately dissolved in DMSO to have three different concentrations (1000, 2000 and 3000) $\mu \mathrm{g} / \mathrm{disc}$. Each of these was separately placed on the surface of the culture media before incubation at $37^{\circ} \mathrm{C}$ for $24 \mathrm{hrs}$. The diameter of zone of inhibition produced by the ligand and its metal(II)complexes was compared with the standard drug, amoxicillin capsule.

\subsection{Antifungal Activity Test}

The in vitro antifungal activity of the Schiff base and its $\mathrm{Mn}$ (II) and $\mathrm{Fe}(\mathrm{II})$ complexes were assayed using three fungal isolates Aspergillus flarus, Aspergillus niger and Mucor indicus using different concentrations (1000, 2000 and 3000) $\mu \mathrm{g} /$ disc by Disc Diffusion Technique. Potato Dextrose Ager (PDA) was used to prepare the culture media and incubated at room temperature for seven days. The results obtained were compared with the activity of Ketoconazole $(200 \mathrm{mg}$ ) as a standard antifungal drug and DMSO as negative control [11].

\section{Results and Discussion}

\subsection{Physical Properties of the Schiff Base and Its Metal(II) Complexes}

The Schiff base and its metal(II) complexes were prepared in good yield, the 
physical properties of the synthesized ligand and its complexes were analyzed and presented in (Table 1). The percentage yield of the ligand was $75 \%$ while that of the complexes were $66 \%$ and $63 \%$. The Schiff base ligand was cotton-like yellow whereas the $\mathrm{Fe}(\mathrm{II})$, and $\mathrm{Mn}(\mathrm{II})$ complexes were light-brown and brown respectively. It was found that the melting point of the ligand was $251^{\circ} \mathrm{C}$ and the decomposition temperature of the metal(II) complexes were $280^{\circ} \mathrm{C}$ and $285^{\circ} \mathrm{C}$, this is an indication of their thermal stability.

The molar conductance of the complexes were 14.89 and $10.76 \Omega^{-1} \cdot \mathrm{cm}^{2} \cdot \mathrm{mol}^{-1}$ for $\mathrm{Mn}$ (II) and $\mathrm{Fe}(\mathrm{II})$ complexes. These low values suggest their non-electrolytic nature as reported by Eman [12]. The effective magnetic moments values of 5.72 and 5.12B.M show the paramagnetic nature of the complexes.

\subsection{Solubility Test}

Some common organic solvents and water were used to ascertain the solubility of the Schiff base and its metal(II) complexes. Also from the result of solubility test presented in (Table 2), the ligand and its metal(II) complexes were found to be soluble in DMSO and dimethylformamide (DMF), insoluble in n-hexane and water and slightly soluble in methanol and $\mathrm{CCl}_{4}$.

\subsection{Elemental Analysis}

The elemental analysis values of the ligand and its metal (II) complexes for $\mathrm{C}, \mathrm{N}$ and $\mathrm{H}$ determined, indicated that the stoichiometry of all the complexes are 1:1 (metal to ligand ratio) and recorded in (Table 3). Also, the elemental analysis details of the ligand suggested the formation of $\mathrm{C}_{17} \mathrm{H}_{14} \mathrm{~N}_{2} \mathrm{O}_{3}$ while that of the complexes revealed the formation of $\left[\mathrm{MnL}\left(\mathrm{H}_{2} \mathrm{O}\right)_{3}\right] \cdot \mathrm{H}_{2} \mathrm{O}$ and $\left[\mathrm{FeL}\left(\mathrm{H}_{2} \mathrm{O}\right)_{3}\right] \cdot \mathrm{H}_{2} \mathrm{O}$. This is in consistent with similar work done by Abubakar [13].

Table 1. Physical properties of the Schiff base ligand and its metal(II) complexes.

\begin{tabular}{ccccccc}
\hline Compounds & Colour & $\begin{array}{c}\% \\
\text { yield }\end{array}$ & $\begin{array}{c}\text { M.P. } \\
\left({ }^{\circ} \mathrm{C}\right)\end{array}$ & $\begin{array}{c}\text { D. Temp. } \\
\left({ }^{\circ} \mathrm{C}\right)\end{array}$ & $\begin{array}{c}\mu f f \\
(\mathrm{~B} . \mathrm{M} .)\end{array}$ & $\begin{array}{c}\text { Molar Conductance } \\
\left(\Omega^{-1} \cdot \mathbf{c m}^{2} \cdot \mathbf{m o l}^{-1}\right)\end{array}$ \\
\hline $\mathrm{L}$ (Ligand) & Yellow & 75 & 251 & - & - & - \\
{$\left[\mathrm{MnL}\left(\mathrm{H}_{2} \mathrm{O}\right)_{3}\right] \cdot \mathrm{H}_{2} \mathrm{O}$} & Brown & 66 & - & 280 & 5.72 & 14.89 \\
{$\left[\mathrm{FeL}\left(\mathrm{H}_{2} \mathrm{O}\right)_{3}\right] \cdot \mathrm{H}_{2} \mathrm{O}$} & Brown & 63 & - & 285 & 5.12 & 10.76 \\
\hline
\end{tabular}

Keys: M.P. = Melting Point, D. Temp. = Decomposition Temperature.

Table 2. Solubility test of the Schiff base ligand and its metal(II) complexes.

\begin{tabular}{cccccccc}
\hline \multirow{2}{*}{ Compound } & \multicolumn{7}{c}{ Solvents } \\
\cline { 2 - 7 } & Acetone & n-hexane & $\mathrm{CCl}_{4}$ & DMF & DMSO & Methanol & water \\
\hline $\mathrm{L}$ (Ligand) & $\mathrm{SS}$ & $\mathrm{IS}$ & $\mathrm{S}$ & $\mathrm{S}$ & $\mathrm{S}$ & $\mathrm{SS}$ & IS \\
{$\left[\mathrm{MnL}\left(\mathrm{H}_{2} \mathrm{O}\right)_{3}\right] \cdot \mathrm{H}_{2} \mathrm{O}$} & $\mathrm{SS}$ & $\mathrm{IS}$ & $\mathrm{SS}$ & $\mathrm{S}$ & $\mathrm{S}$ & $\mathrm{SS}$ & IS \\
{$\left[\mathrm{FeL}\left(\mathrm{H}_{2} \mathrm{O}\right)_{3}\right] \cdot \mathrm{H}_{2} \mathrm{O}$} & $\mathrm{SS}$ & $\mathrm{IS}$ & $\mathrm{SS}$ & $\mathrm{S}$ & $\mathrm{S}$ & $\mathrm{SS}$ & IS \\
\hline
\end{tabular}

Keys: $\mathrm{S}=$ Soluble, $\mathrm{SS}=$ Slightly Soluble, and IS = Insoluble. 


\subsection{FTIR Analysis}

The infra red spectral analysis of the ligand and its metal(II) complexes were determined. The band observed at $3339 \mathrm{~cm}^{-1}$ (Figure 1) in the Schiff base is attributed to $\mathrm{r}(\mathrm{OH})$, and it disappeared in the metal(II) complexes, which indicate the participation of phenolic oxygen atom in bonding with the respective metal(II) ions. Similar result was reported by Abdullahi and Gareth [14]. The broad band at $3387 \mathrm{~cm}^{-1}$ and $3335 \mathrm{~cm}^{-1}$ (Figure 2) in the complexes spectra are assigned to water of hydration as reported in the work of El-ajaily et al. [15] [16]. The FTIR spectral details of the Schiff base determined displayed a band at 1622 $\mathrm{cm}^{-1}$ and it was attributed to $v(\mathrm{C}=\mathrm{N})$, a feature of azomethine group. The same band was observed to shift to lower frequencies 1614 and $1573 \mathrm{~cm}^{-1}$ (Figure 3)

Table 3. Elemental analysis data of the Schiff base and its metal(II) complexes.

\begin{tabular}{ccccc}
\hline \multirow{2}{*}{ Compound } & \multicolumn{4}{c}{ Found/(Calculated) \% } \\
\cline { 2 - 5 } & $\% \mathbf{N}$ & $\% \mathrm{C}$ & $\% \mathbf{H}$ & $\% \mathbf{~ M}$ \\
\hline $\mathrm{L}$ (Ligand) & 8.90 & 64.39 & 4.18 & - \\
{$\left[\mathrm{MnL}\left(\mathrm{H}_{2} \mathrm{O}\right)_{3}\right] \cdot \mathrm{H}_{2} \mathrm{O}$} & $6.34(6.68)$ & $49.02(48.70)$ & $4.73(4.81)$ & 13.10 \\
{$\left[\mathrm{FeL}\left(\mathrm{H}_{2} \mathrm{O}\right)_{3}\right] \cdot \mathrm{H}_{2} \mathrm{O}$} & $7.02(6.67)$ & $48.09(48.59)$ & $5.10(4.81)$ & 13.29 \\
\hline
\end{tabular}

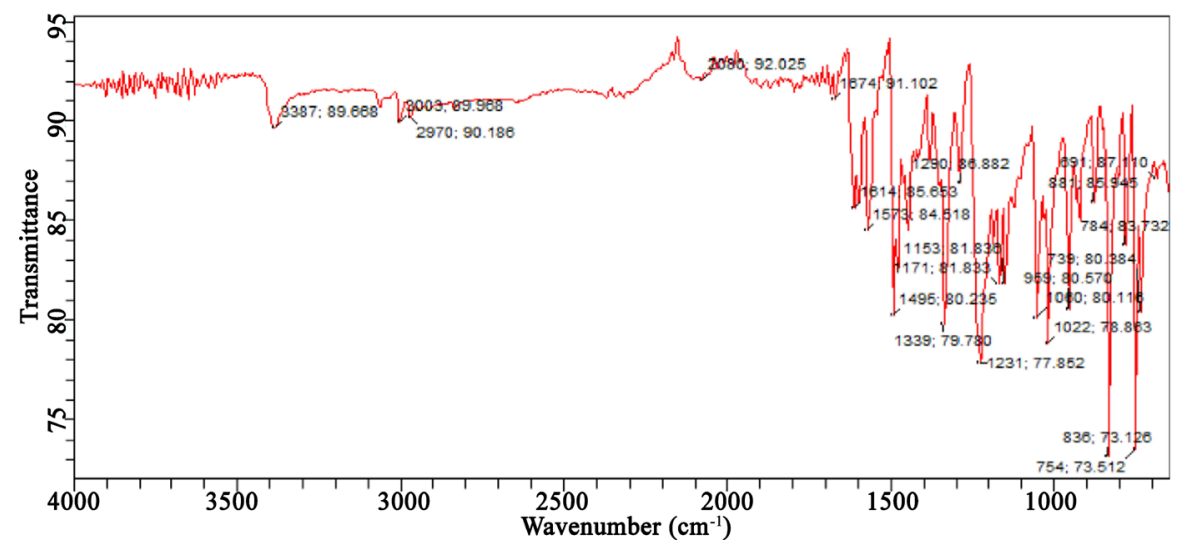

Figure 1. FTIR of Schiff base ligand.

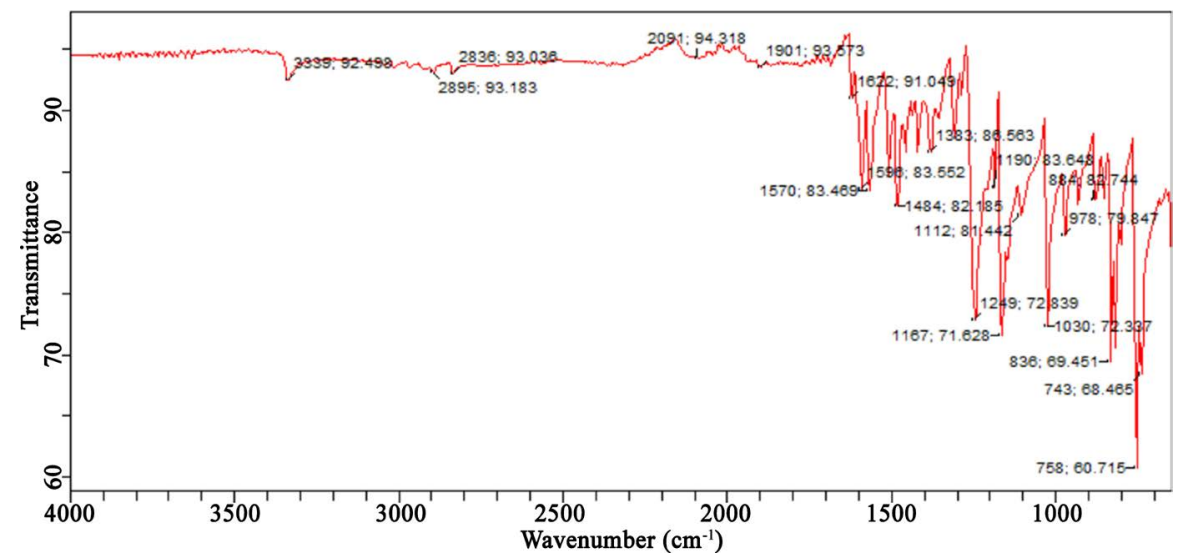

Figure 2. FTIR of Mn(II) complex. 
in the complexes suggesting coordination of the ligand to the respective metal(II) ions [17] [18]. New bands in the metal(II) complexes appeared and they are assigned to $v(\mathrm{M}-\mathrm{N})$, stretching frequencies (Table 4).

\subsection{Antimicrobial and Antifungal Activity}

The antimicrobial actvity results of the screened ligand and its metal(II) complexes were given in the Table 5 and Table 6 . The ligand and its complexes were screened for their antibacterial activities against the selected bacteria isolates of

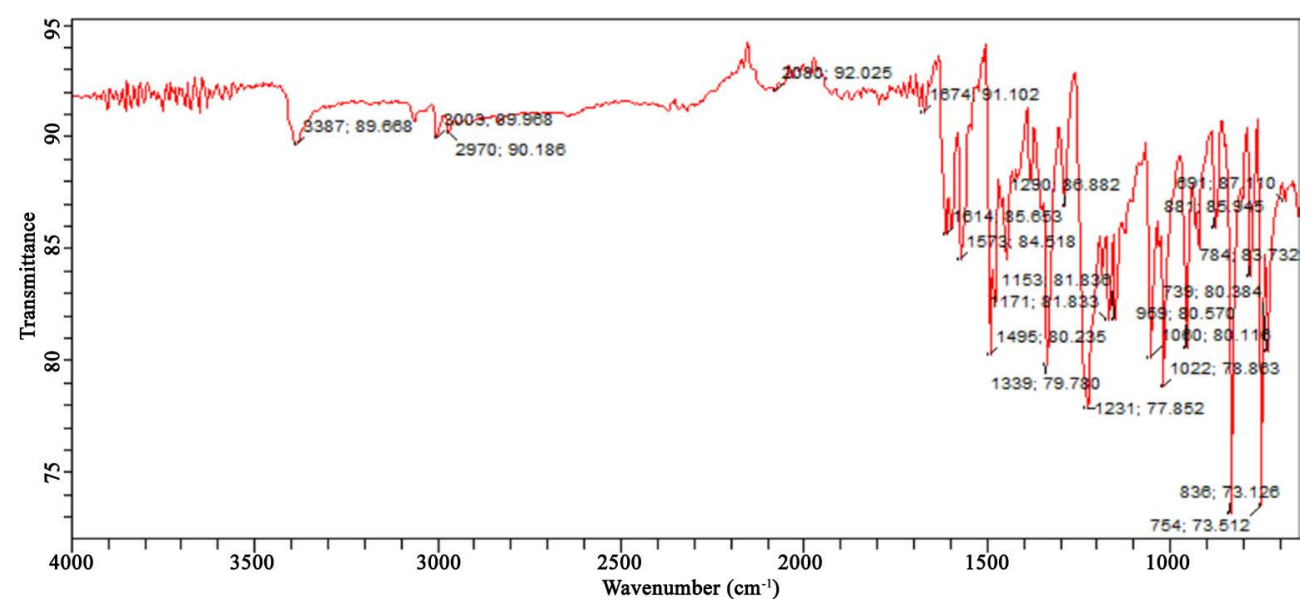

Figure 3. FTIR of Fe(II) complex.

Table 4. Infrared spectral data of the Schiff base and its metal(II) complexes.

\begin{tabular}{|c|c|c|c|c|c|c|}
\hline Compound & $\begin{array}{c}\mathrm{OH} \\
\left(\mathrm{cm}^{-1}\right)\end{array}$ & $\begin{array}{c}v \mathrm{H}_{2} \mathrm{O} \\
\left(\mathrm{cm}^{-1}\right)\end{array}$ & $\begin{array}{l}v C=N \\
\left(\mathrm{~cm}^{-1}\right)\end{array}$ & $\begin{array}{l}\qquad \mathrm{C}-\mathrm{O} \\
\left(\mathrm{cm}^{-1}\right)\end{array}$ & $\begin{array}{l}v \mathrm{M}-\mathrm{N} \\
\left(\mathrm{cm}^{-1}\right)\end{array}$ & $\begin{array}{l}v \mathrm{M}-\mathrm{O} \\
\left(\mathrm{cm}^{-1}\right)\end{array}$ \\
\hline L (Ligand) & 3339 & - & 1622 & 1383 & - & - \\
\hline$\left[\mathrm{MnL}\left(\mathrm{H}_{2} \mathrm{O}\right)_{3}\right] \cdot \mathrm{H}_{2} \mathrm{O}$ & - & 3387 & 1614 & 1235 & 562 & 687 \\
\hline$\left[\mathrm{FeL}\left(\mathrm{H}_{2} \mathrm{O}\right)_{3}\right] \cdot \mathrm{H}_{2} \mathrm{O}$ & - & 3335 & 1573 & 1231 & 581 & 762 \\
\hline
\end{tabular}

Table 5. Antibacterial activity on the Schiff base Ligand and its metal(II) complexes.

\begin{tabular}{ccccc}
\hline \multirow{2}{*}{ Compound } & $\begin{array}{c}\text { Concentration } \\
\left(\mu \mathrm{g} \cdot \mathrm{cm}^{-3}\right)\end{array}$ & $\begin{array}{c}\text { Staphylococcus } \\
\text { aureus }\end{array}$ & $\begin{array}{c}\text { Eschirichia } \\
\text { coli }\end{array}$ & Salmonella typhi \\
\cline { 3 - 5 } & 1000 & 07 & 09 & 08 \\
$\mathrm{~L}$ (Ligand) & 2000 & 06 & 08 & 10 \\
& 3000 & 09 & 07 & 09 \\
{$\left[\mathrm{MnL}\left(\mathrm{H}_{2} \mathrm{O}\right)_{3}\right] \cdot \mathrm{H}_{2} \mathrm{O}$} & 1000 & 09 & 10 & 11 \\
& 2000 & 11 & 13 & 13 \\
& 3000 & 13 & 18 & 16 \\
{$\left[\mathrm{FeL}\left(\mathrm{H}_{2} \mathrm{O}\right)_{3}\right] \cdot \mathrm{H}_{2} \mathrm{O}$} & 1000 & 11 & 11 & 10 \\
& 2000 & 12 & 15 & 15 \\
& 3000 & 16 & 18 & 14 \\
\hline
\end{tabular}


Table 6. Antifungal activity on the Schiff base Ligand and its metal(II) complexes.

\begin{tabular}{ccccc}
\hline \multirow{2}{*}{ Compound } & $\begin{array}{c}\text { Concentration } \\
\left(\mu \mathrm{g} \cdot \mathrm{cm}^{-3}\right)\end{array}$ & \multicolumn{3}{c}{ Fungal inhibition zones (mm) } \\
\cline { 3 - 5 } & 1000 & 06 & 03 & 04 \\
\hline $\mathrm{L}$ (Ligand) & 2000 & 08 & 05 & 06 \\
& 3000 & 09 & 07 & 07 \\
& 1000 & 10 & 11 & 12 \\
{$\left[\mathrm{MnL}\left(\mathrm{H}_{2} \mathrm{O}\right)_{3}\right] \cdot \mathrm{H}_{2} \mathrm{O}$} & 2000 & 12 & 16 & 15 \\
& 3000 & 20 & 20 & 19 \\
& 1000 & 11 & 09 & 11 \\
{$\left[\mathrm{FeL}\left(\mathrm{H}_{2} \mathrm{O}\right)_{3}\right] \cdot \mathrm{H}_{2} \mathrm{O}$} & 2000 & 15 & 12 & 14 \\
& 3000 & 18 & 17 & 17 \\
& & & & Asphergillus niger \\
\hline
\end{tabular}

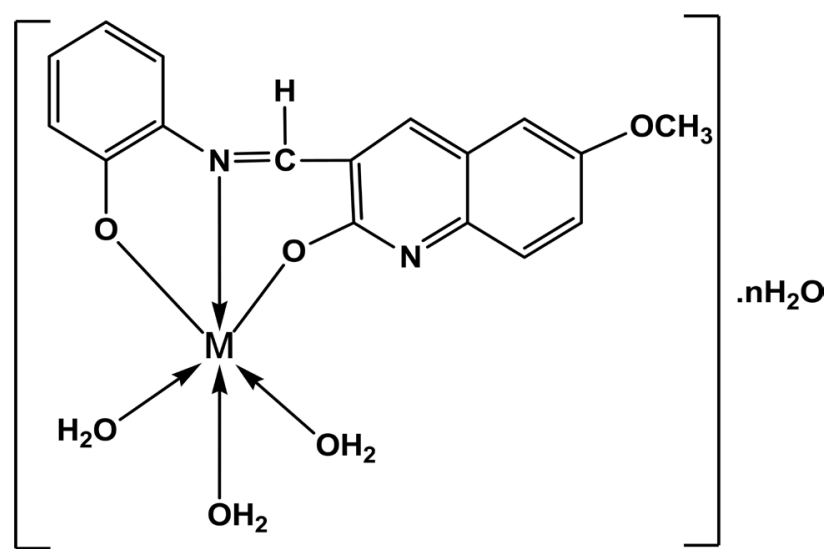

Figure 4. Proposed general molecular structure of metal(II) complexes.

Eschirichia coli, Salmonella typhi and Staphylococcus aureus, by disc diffusion method (Table 5). It was discovered that the metal(II) complexes possess more effect in inhibiting the microbial growth. This is possibly because of the interaction of the metal(II) complexes with lipoproteins of the cell. Therefore the metal(II) complexes can restrict the usual functioning of the microbial cell. Furthermore, higher stability of the complexes at higher temperature can also allow them to be used as a potential antimicrobial agent. Similar result was also recorded in Table 6 for antifungal activity shown by selected fungi isolates of $A s^{-}$ pergillus flarus, Asphergillus niger and Mucor iudicus respectively (Table 6).

\section{Conclusion}

Schiff base with its metal(II) complexes was synthesized and characterized (Figure 4). The molar conductance values of the metal(II) complexes obtained were low, indicating the non electrolytic behavior of the metal(II) complexes. The elemental analysis data suggested 1:1 (metal to ligand ratio). The infrared data indicated that the ligand was coordinated to the central metal(II) ion in a tridentate manner via the azomethine nitrogen and phenolic oxygen atoms after 
deprotonation. The result of the solubility tests showed that the ligand and its metal(II) complexes were soluble in dimethylsulphoxide (DMSO) and dimethylformamide (DMF), slightly soluble in acetone and ethanol and insoluble in water and n-hexane. The metal(II) complexes were found to be more active than the ligand but less than the reference drugs Amoxicillin and Ketoconazole used.

\section{Conflicts of Interest}

The authors declare no conflicts of interest regarding the publication of this paper.

\section{References}

[1] Aliyu, H.N. (2018) Schiff Bases and Their Metal Complexes: The Drugs for the Next Generation. Professorial Inaugural Lecture Series. Bayero University, Kano, Nigeria.

[2] Yahyazadeh, A. and Azimi, V. (2013) Synthesis of Some Unsymmetrical New Schiff. European Chemical Bulletin, 2, 453-455.

[3] Chaudary, N.K. (2012) Synthesis and Medicinal Use of Metal Complexes of Schiff Bases. BIBECHANA, 9, 72-80. https://doi.org/10.3126/bibechana.v9i0.7178

[4] Zoubi, W.A. (2013) Biological Activities of Schiff Bases and Their Complexes: A Review of Recent Works. International Journal of Organic Chemistry, 3, 73-95. https://doi.org/10.4236/ijoc.2013.33A008

[5] Arulmurugan, S., Kavitha, H.P. and Venkatraman, B.R. (2010) Biological Activities of Schiff Base and Its Complexes: A Review. Rasayan Journal of Chemistry, 3, 385-410.

[6] Emriye, A.Y. (2016) Synthesis and Characterization of Schiff Base. 1-Amino-4Methylpiperazine Derivatives. CBU Journal of Sciences, 12, 375-392.

[7] Savithri, K. and Revanasiddappa, H.D. (2018) Synthesis and Characterization of Oxidovanadium (IV) Complexes of 2-((E)-(6Fluorobenzo[d]thiazol-2-ylimino)methyl)-6-methoxyphenol and Their Antimicrobial, Antioxidant, and DNA-Binding Studies. Bioinorganic Chemistry and Applications, 2018, Article ID: 2452869. https://doi.org/10.1155/2018/2452869

[8] Qin, W., Long S., Panunzio, M. and Biondi, S. (2013) Schiff Bases: A Short Survey on an Evergreen Chemistry Tool. Molecules, 18, 12264-12289.

https://doi.org/10.3390/molecules181012264

[9] Wang, L., Wang, Y., Hou, Z. and Liu, Y. (2012) Synthesis and Fluorescence Property of Novel Zn2+ Schiff Base Complex. Advanced Materials Research, 535-537, 1237-1240. https://doi.org/10.4028/www.scientific.net/AMR.535-537.1237

[10] Ashraf, M.A. Mahmood, A. and Wajid, A. (2017) Synthesis, Characterization and Biological Actibity of Schiff Bases. International Conference on Chemistry and Chemical Process, 4, 25-37.

[11] Jorgensen, J.H. and Turnidge, J.D. (2003) Susceptibility Test Methods: Dilution and Disk Diffution Methods. Manual of Clinical Microbiology. 8th Edition, American Society of Microbiology, Washington DC, 1108-1127.

[12] Eman, T.S. (2015) Synthesis, Characterization and Spectroscopic Studies of 2-\{\{E\}Hydroxyphenyl) imino) methyl $\}$ Phenol Schiff Base with Some Metal Complexes. Journal of Al-Nahrain University, 18, 39-45. https://doi.org/10.22401/JNUS.18.1.05

[13] Abubakar, A.A., Yusuf, Y. and Hussaini, A.U. (2017) Synthesis and Characteriza- 
tion of $\mathrm{Cu}(\mathrm{II})$ and $\mathrm{Zn}$ (II) Schiff Base Complexes. International Journal of Science and Applied Research, 2, 8-16.

[14] Abdullahi, O.S. and Gareth, M.W. (2013) Antimicrobial activity and Cu(II) Complexes of Schiff Bases Derived from Orthoaminophenol and Salicylaldehyde Derivatives. Journal of Chemical and Pharmaceutical Research, 5, 147-154.

[15] Siddappa, K. and Reddy, P.C. (2012) Siddappa, Synthesis, Spectral Characterization and Antimicrovial Studies of Transition Metal(II) Complexes with Schiff Base 3-[92-hydroxy-6-methoxyquinoline3-ylmethylene)-amino]-2-methyl-3H-quinoline -4-one. International Journal of Applied Biology and Pharmaceutical Technology, 3 , 168-176.

[16] El-ajaily, M.M., Maihub, A.A., Hudere, S.S. and Ben Saber, S.M. (2006) Nickel(II) Chelate of Schiff Base Derived from 4-Dimethylaminobenzaldehyde with Cysteine. Asian Journal of Chemistry, 18, 2427-2430.

[17] Mounika, K., Anupama, B., Pragathi, J. and Gyanakumari, C. (2010) Synthesis, Characterization and Biological Activity of a Schiff Base Derived from 3-Ethoxy Salicyladehyde and 2-Amino Benzoic Acid and Its Transition Metal Complexes. Journal of Scientific Research, 2, 513-524. https://doi.org/10.3329/jsr.v2i3.4899

[18] Rasha, S.J. and Farah, M.I. (2012) Synthesis and Characterization of Tetradentate Bissalicylaldehyde Schiff Base with Some Transition Metal Complexes. The First Scientific Conference of the College of Education for Pure Sciences, AL-Nahrain University, 25-26 April 2020, 124-131. 